\title{
Determining Behavior to Uptake and Its Predictors toward Cervical Cancer Screening among Women: A Case- Control Multistage Study
}

\author{
Eko Winarti ${ }^{1 *} \oplus$, Dhita Kris Prasetyanti ${ }^{2} \oplus$, Moh Alimansur ${ }^{3} \oplus$, Rozzana \\ Mohd Said ${ }^{4} \odot$ \\ ${ }^{1,2} \mathrm{Faculty}$ of Health Sciences, College of Midwifery, Universitas Kadiri, Kediri, Indonesia \\ ${ }^{3}$ Collage of Nursing, Akademi Keperawatan Dharma Husada, Kediri, Indonesia \\ ${ }^{4}$ Faculty of Health Sciences, Universiti Teknologi MARA, Selangor, Malaysia
}

\begin{abstract}
Background: Cervical cancer is a primary cause of mortality cancer among Indonesian women. Notwithstanding these threats, cervical cancer screening services have low uptake. Additionally, there was a lack of multistage casecontrol studies regarding positive behavior and its determinants for cervical cancer screening.

Purpose: This study was to ascertain the uptake behavior and its predictors toward cervical cancer screening.

Methods: A case-control study was conducted in Kediri with a sample size of 410 using multistage random sampling (ratio 1:1) from nine community health services and data were collected between June 11 to September 18, 2019. Data were obtained through questionnaires and assessed using Chisquare, Independent t-test, and multiple logistic regression with adjusted odds ratio (AOR).

Results: Behavior of cervical cancer screening was related to knowledge $(A O R=1.61)$, husband support $(A O R=1.38)$, social support $(A O R=5.03)$, external motivation $(A O R=1.24)$, internal motivation $(A O R=1.37)$, perceived susceptibility $(A O R=1.49)$, perceived barrier $(A O R=0.74)$, perceived benefit $(A O R=0.73)$, perceived severity $(A O R=1.36)$, self-efficacy $(A O R=1.30)$, perceived threat $(A O R=1.26)$, and intention to screening $(A O R=3.06)$ with $\mathrm{p}$ value $<0.05$ after adjusting covariate factors.

Conclusion: Knowledge, husband and social support, external and internal motivation, all domains of health belief, and intention to uptake screening were found to be strongly associated with behavior to uptake cervical cancer screening.
\end{abstract}

Keywords: cervical cancer; health belief; intention; motivation; screening.

\section{Introduction}

Cancer is a major public health concern all over the world and it was responsible for 530,000 to 570,000 new cases occurred with 270,000 to 311,000 of fatalities worldwide from 2012 to 2018 (Arbyn et al., 2020). Moreover, approximately $90 \%$ of fatalities occurred in low-income and middleincome countries in 2018 (Arbyn et al., 2020). The incidence of mortality rate was generally two-fold to three-fold higher in developed countries compared with low-income and middle-income countries (DeSantis et al., 2015) .

Indonesia has a high prevalence of both incident and fatalities estimates of 13,762 and 7,493 , respectively. These estimates make cervical cancer the second most frequently diagnosed cancer in Indonesian women, after breast cancer, and also the leading cause of cancer mortality rate (Jaspers, Budiningsih, Wolterbeek, Henderson, \& Peters, 2011). To produce considerable reduction in cervical cancer incidence and mortality through increased acceptance of cervical cancer screening services, such barriers must be addressed (Rahayu \& Ochoa, 2015). 
Remarkably, the target population for screening tests in Indonesia was 37,415,483 women (29.07\%), with $3,040,116$ women (8.12\%) undergoing examinations up to 2017 (Kementerian Kesehatan, 2017). In East Java Province, there were 6,278,356 women $(31.72 \%)$ targeted for cervical cancer screening assessment, but only $1.4 \%$ performed to screening (Kementerian Kesehatan, 2017). Interestingly, according to statistics from the Kediri's Health Office Center, the coverage of early detection of cervical cancer in 2014 almost reached 1\% of the target established by the health government of Kediri, which was 10\% (Muhith et al., 2020). This challenge indicated that potential factors for behavior to uptake cervical cancer screening are comprehensive identified. These factors include demographic characteristics and factors related to knowledge, health belief, motivation and intention to uptake the screening test (Bayu, Berhe, Mulat, \& Alemu, 2016; Ebu, Mupepi, Siakwa, \& Sampselle, 2015; Roncancio et al., 2015). Consequently, these factors may contribute to enhancing cervical cancer screening.

Women's insufficient knowledge of preventive cervical cancer indicated low self-perception of disease risk and low utilization of screening services program (Ebu et al., 2015). Interestingly, the previous study done among Indonesian parents, female undergraduate student, and adult women showed a low level of knowledge regarding the screening test of cervical cancer (Endarti, Satibi, Farida, Rahmawanti, \& Andriani, 2018; Jaspers et al., 2011). Furthermore, these studies were limited to screening service focused on women, and offered little insight into cervical cancer screening especially knowledge of the vaccine among populations with community multistage study in Indonesia. Therefore, the knowledge of the disease amongst women in Indonesia remains clarified.

The health belief model (HBM) is one of the theoretical guidelines for health lifestyle practices in epidemiology and behavior study. Moreover, the HBM is common and widely accepted due to its high prediction accuracy (Daryani, Shojaeezadeh, Batebi, Charati, \& Naghibi, 2016; Rosenstock, Strecher, \& Becker, 1988). The HBM has a strong correlation with how women assess the challenges and difficulties they could encounter when adopting new practices related to health, especially the behavior to conduct cervical cancer screening. These highlights, the probability of an individual behavior is the greatest when the individual is both motivated to act and has formed tactics and plans that facilitate behavioral engagement. The interconnections between motivation and behavior are required to establish better understanding of the success of behavioral performance screening to intention screening tests $(\mathrm{Gu}$, Chan, He, Choi, \& Yang, 2013), but these interconnections require explored.

Social support such as husband support and social support was considered to be a motivation for women to get routine cancer screenings (Mouttapa et al., 2016). Currently, incorporating social support messages into interventions may be a straightforward successful method for increasing women's screening test (Greibe Andersen, Shrestha, Gyawali, Neupane, \& Kallestrup, 2020). Sometimes, intention is one of the most widely used theories of planned behavior (TPB) to clarify the interaction between intention and behavior to perform cervical cancer screening (Ogilvie et al., 2016).

Remarkably, several studies examine behavioral determinants including health beliefs, motivation, social support and intention (Daryani et al., 2016; Zare et al., 2016). However, there are no studies examining this relationship based on behavioral theory regarding cervical cancer screening with a multistage case-control study among Indonesian women living in Kediri, East Java Province. The findings of this research were to determine the knowledge, intention, motivation, and social support, as well as health belief constructs, that influence cervical cancer screening behavior among Indonesia women in area.

\section{Methods}

This research collected data using a case-control study (1:1 ratio) between June 11 to September 18, 2019. Sampling was carried out using a multistage simple random sampling method, where the researcher took samples through a stratified process and similar with other implemented of multistage random sampling in the health community center (Rias, Gordon, et al., 2020; Rias, Kurniasari, et al., 2020).

This research has received approval from the Ethics committee of Universitas Airlangga with registration number 38/KEPK/UA/II date on and duration. The first stage; determine the number of samples that must be taken at each District Health Center in Kediri with a proportional population; there were 46 respondents from Sukorame Health Center, Selatan Health Center with 50 respondents, Utara Health Center with 36 respondents, Ngletih Health Center with 96 respondents, Pesantren I Health Center with 50 respondents, Campurejo Health Center with 4 respondents, Mrican Health Center with 26 respondents, Balowerti Health Center with 86 respondents, and Pesantren II Health Center with 16 respondents. The second stage; determine the selected district community health center in each community health center randomly. The third stage; respondents in each district were selected by simple random sampling. Both women conduct-case and not conduct-control screening cervical cancer were recruited from nine primary clinics in community and were assessed using medical record and brief interview aimed to assess behavioral uptake a cervical cancer screening and the cancer family history.

Additionally, physicians and principal author independently evaluated the clinic medical records 
Determining Behavior to Uptake and Its Predictors

Table 1. Characteristics of The Respondent

\begin{tabular}{lcc}
\hline \multicolumn{1}{c}{ Variables } & $\mathbf{n}$ & $\%$ \\
\hline Age & & \\
$20-35$ & 160 & 39.0 \\
$>35-50$ & 250 & 61.0 \\
Education & & 40.0 \\
ISCED $<3$ & 164 & 60.0 \\
ISCED $\geq 3$ & 246 & \\
Occupation & & 70.5 \\
Unemployed workers & 289 & 29.5 \\
Employed workers & 121 &
\end{tabular}

\section{Income (IDR)}

$<1.47$ million

\begin{tabular}{|c|c|c|}
\hline \multicolumn{3}{|l|}{ Cancer family history } \\
\hline No & 395 & 96.3 \\
\hline Yes & 15 & 3.7 \\
\hline Knowledge (Mean \pm SD) & 4.89 & 1.59 \\
\hline Husband support (Mean \pm SD) & 15.62 & 1.98 \\
\hline Social support (Mean \pm SD) & 4.77 & 1.10 \\
\hline External motivation (Mean \pm SD) & 19.86 & 3.33 \\
\hline Internal motivation (Mean \pm SD) & 22.16 & 2.61 \\
\hline Perceived susceptibility (Mean \pm SD) & 16.32 & 3.54 \\
\hline Perceived barriers (Mean \pm SD) & 23.04 & 4.78 \\
\hline Perceived benefits (Mean \pm SD) & 23.13 & 3.21 \\
\hline Perceived severity (Mean \pm SD) & 20.65 & 3.13 \\
\hline Perceived self-efficacy (Mean \pm SD) & 27.06 & 4.88 \\
\hline Perceived threat (Mean \pm SD) & 25.73 & 3.73 \\
\hline Intention to screening (Mean \pm SD) & 12.04 & 1.89 \\
\hline
\end{tabular}

Note: IDR = Indonesian Rupiah rate; ISCED = International Standard Classification of Education;

$S D=$ Standard Deviation

of the qualifying case and control groups. The sample size calculation in this study is based on the rule of thumb (Aguinis \& Harden, 2010), which states that the sample size should be large enough to include at least five to ten observations for each estimated parameter with under estimation rate of $20 \%$. In total, 410 participants, 205 women who do not conduct screening, and 205 women who conduct screening, were consecutively recruited. Thus, all participants agreed to participate in the study.

The sample case study included women who were married, aged between 20 to 39 years, who confirmed not pregnant and had carried out to detection of cervical cancer using the visual acetate acid inspection method or pap smear screening test. The control group is some women who are married, not pregnant but have not carried out early detection of cervical cancer screening. Both case and control respondents excluded those who were pregnant, had a Mini-Mental State Exam score of $\leq 24$, and disability or used antidepressant as well as not completing the questionnaire. All across the observation period, trained nurses and authors questioned all participants using a questionnaire that included questions about participants' demographic data, such as age, education, occupation, income and cancer family history. Additionally, clinical related health factors including knowledge, husband support, social support, both external and internal motivation, all domains of health belief model, as well as the intention to uptake screening were evaluated.

The respondents' general knowledge was consisting of 9 question items regarding information related to the early detection of cervical cancer and cognitive construct (Waller, Ostini, Marlow, McCaffery, \& Zimet, 2013). We interpreted the score with "wrong (0-point)" and "correct (1-point)" and the total possible lower score was 0-9; which indicated that a higher score suggests greater familiarity with knowledge of cervical cancer screening. The Indonesian version of knowledge questionnaire had 
Table 2. Relationships of Distributions of Demographic with Intention to Uptake in Cervical Cancer Screening

\begin{tabular}{|c|c|c|c|}
\hline \multirow[b]{2}{*}{ Variables } & \multicolumn{2}{|c|}{$\begin{array}{c}\text { Behavior to uptake in cervical cancer } \\
\text { screening, } n(\%)\end{array}$} & \multirow{2}{*}{$p$ value } \\
\hline & $\begin{array}{l}\text { Not conduct screening } \\
(n=205)\end{array}$ & $\begin{array}{l}\text { Conduct screening } \\
(n=205)\end{array}$ & \\
\hline \multicolumn{4}{|l|}{$\mathrm{Age}^{\mathrm{a}}$} \\
\hline $20-35$ & $95(46.3)$ & $65(31.7)$ & 0.002 \\
\hline $35-50$ & $110(53.7)$ & $140(68.3)$ & \\
\hline \multicolumn{4}{|l|}{ Education $^{a}$} \\
\hline ISCED $<3$ & $79(38.5)$ & $85(41.5)$ & 0.545 \\
\hline ISCED $\geq 3$ & $126(61.5)$ & $120(58.5)$ & \\
\hline \multicolumn{4}{|l|}{ Occupation ${ }^{\mathrm{a}}$} \\
\hline Unemployed workers & $129(62.9)$ & $160(78.0)$ & 0.001 \\
\hline Employed workers & $76(37.1)$ & $45(22.0)$ & \\
\hline \multicolumn{4}{|l|}{ Income (IDR) ${ }^{a}$} \\
\hline$<1.47$ million & $85(41.5)$ & $74(36.1)$ & 0.265 \\
\hline$\geq 1.47$ million & $120(58.5)$ & $131(63.9)$ & \\
\hline \multicolumn{4}{|l|}{ Cancer family history ${ }^{a}$} \\
\hline No & $202(98.5)$ & $193(94.1)$ & 0.018 \\
\hline Yes & $3(1.5)$ & $12(5.9)$ & \\
\hline Knowledge (Mean \pm SD) $)^{b}$ & $4.21(1.46)$ & $5.56(1.41)$ & $<0.001$ \\
\hline Husband support (Mean \pm SD) ${ }^{b}$ & $15.07(2.18)$ & $16.18(1.69)$ & $<0.001$ \\
\hline Social support (Mean \pm SD) $)^{b}$ & $4.20(1.07)$ & $5.33(0.71)$ & $<0.001$ \\
\hline External motivation (Mean $\pm \mathrm{SD})^{\mathrm{b}}$ & $18.93(3.09)$ & $20.79(3.31)$ & $<0.001$ \\
\hline Internal motivation (Mean \pm SD) ${ }^{b}$ & $20.89(1.55)$ & $23.43(2.83)$ & $<0.001$ \\
\hline Perceived susceptibility (Mean $\pm \mathrm{SD})^{\mathrm{b}}$ & $14.33(2.70)$ & $18.32(3.15)$ & $<0.001$ \\
\hline Perceived barriers (Mean \pm SD) ${ }^{b}$ & $24.27(3.90)$ & $21.80(5.42)$ & $<0.001$ \\
\hline Perceived benefits (Mean $\pm \mathrm{SD})^{\mathrm{b}}$ & $22.52(3.26)$ & $23.74(3.06)$ & $<0.001$ \\
\hline Perceived severity (Mean \pm SD) ${ }^{b}$ & $19.19(2.62)$ & $22.12(2.91)$ & $<0.001$ \\
\hline Perceived self-efficacy (Mean \pm SD) ${ }^{b}$ & $24.58(4.33)$ & $29.54(4.08)$ & $<0.001$ \\
\hline Perceived threat (Mean \pm SD) $)^{b}$ & $23.56(3.15)$ & $27.82(3.02)$ & $<0.001$ \\
\hline Intention to screening (Mean \pm SD) ${ }^{b}$ & $10.90(1.89)$ & $13.17(1.01)$ & $<0.001$ \\
\hline
\end{tabular}

Note: IDR = Indonesian Rupiah rate; ISCED = International Standard Classification of Education;

$S D=$ Standard Deviation; ${ }^{a}$ Chi-Square $;{ }^{b}$ Independent $t$ - test

good internal consistency with Cronbach's alpha was 0.689 for our study.

The constructs for the HBM were a 5-likert scale ( 1 being extremely dissatisfied and 5 being extremely dissatisfied), and study with continuous data was developed by the researcher and obtained from Champion (Champion \& Skinner, 2008) to adjust the scale and make required improvements to make them valid for both Bahasa Indonesia and the culture, consisting of 49 items, involving 6 items for susceptibility, severity 7 -items, benefit 7 -items, barrier 11-items, self-efficacy 9-items, and threat 9 items. The questionnaire's content validity was determined by 5 experts in nursing and public health with content validity 0.91 and internal validity of questions was acceptable reliability with Cronbach's alpha coefficient of $0.746,0.768,0.802,0.781$, $0.774,0.758$ in perceived susceptibility, severity, benefit, barrier, self-efficacy, and threat, respectively. The motivation questionnaire was developed and has been modified by researchers based on the motivational theory (Reiss, 2012) related to women's motivation in carrying out early detection of cervical cancer. This variable questionnaire consists of 15 question items (external motivation with 8-items, and internal motivation with 7-items), using a Likert scale consisting answer choices from strongly agree score $=4$, agree score $=3$, disagree score $=2$ and strongly disagree score $=1$. Higher score indicated those with good motivation. In our study, the content validity was 0.87 with acceptable Cronbach's alpha coefficient of 0.796 and 0.789 in 
Table 3. Adjusted beta-coefficients and 95\% confidence intervals (Cls) of knowledge, support, motivation, intention to screening and HBM constructs with participants' behavioral to uptake in cervical cancer screening

\begin{tabular}{|c|c|c|}
\hline \multirow[b]{2}{*}{ Variables } & \multicolumn{2}{|c|}{ Behavioral to uptake in cervical cancer screening, $\mathrm{n}(\%)$} \\
\hline & $\begin{array}{c}\text { Unadjusted OR }(95 \% \mathrm{Cl}), \mathrm{p} \\
\text { value }\end{array}$ & AOR $(95 \% \mathrm{Cl})$, $\mathrm{p}$ value \\
\hline Knowledge & $1.89(1.62 \sim 2.21),<0.001$ & 1.61 (1.09 2.38), 0.017 \\
\hline Husband support & $1.37(1.22 \sim 1.54),<0.001$ & 1.38 (1.04 1.81), 0.024 \\
\hline Social support & 3.47 (2.69 4.49), <0.001 & 5.03 (2.26 11.19), 0.001 \\
\hline External motivation & $1.20(1.12 \sim 1.28),<0.001$ & 1.24 (1.02 1.51), 0.032 \\
\hline Internal motivation & $1.70(1.50 \sim 1.93),<0.001$ & 1.37 (1.04 1.80), 0.026 \\
\hline Perceived susceptibility & $1.57(1.43 \sim 1.72),<0.001$ & 1.49 (1.20 1.86), 0.001 \\
\hline Perceived barriers & $0.88(0.84 \sim 0.93),<0.001$ & $0.74(0.62 \sim 0.89), 0.001$ \\
\hline Perceived benefits & $1.13(1.06 \sim 1.21),<0.001$ & $0.73(0.58 \sim 0.93), 0.009$ \\
\hline Perceived severity & $1.50(1.36 \sim 1.66),<0.001$ & 1.36 (1.05 1.75), 0.018 \\
\hline Perceived self-efficacy & $1.33(1.25 \sim 1.42),<0.001$ & 1.30 (1.08 1.55), 0.005 \\
\hline Perceived threat & 1.65 (1.49 1.83), <0.001 & 1.26 (1.01 1.57), 0.038 \\
\hline Intention to screening & $2.69(2.23 \sim 3.25),<0.001$ & 3.06 (1.99 4.71), 0.001 \\
\hline
\end{tabular}

Note: Adjusted b coefficients and 95\% Cl were estimated using multiple logistic regression after adjusting for age, education, occupation, income and cancer family history. $\mathrm{Cl}=$ confidence interval; OR = odds ratio; $A O R=$ adjusted odds ratio.

internal and external motivation, respectively. The support system instrument used by the researcher to collect data on husband's support and social support was adopted from the Partner Interaction Questionnaire (Cohen \& Lichtenstein, 1990), which was modified by the researcher to husbands support and social support regarding the implementation of early detection of cervical cancer. The questionnaire consists of 9 items for husband support and 3 items for social support question items; if the answer is "yes = score 2", and for the answer is "no = score 1". Higher score indicated good support system. In our study, the content validity was 0.95 with acceptable Cronbach's alpha coefficient of 0.786 and 0.803 in husbands support and social support, respectively. Intentions to screening questionnaire were adapted from the self-administered TPB questionnaire (Ajzen, 1991) and developed to cervical cancer screening with 7 items. We interpreted the score with "no (1-point)" and "yes (2-point)" and the total possible lower score was 1-14; which indicated that a higher score suggests strong intention of cervical cancer screening. The Indonesian version of Intentions to screening questionnaire had good internal consistency with Cronbach's alpha of 0.718 in our study.

Descriptive analyses were used to determined sociodemographic data, knowledge, husband support, social support, both external and internal motivation, all domains of health belief model, as well as the intention to uptake screening between groups. The outcomes are showed as percentages (\%), frequency (n) or mean $\square$ standard deviation (SD). The differences significance was calculated using a Chi-square and Independent t-test. The relation between outcome and the predictor variables was determined using simple logistic regression, used to calculate the odds ratio (ORs) and measure the association between determinates factors and behaviors cervical cancer screening in the analytical bivariate. Moreover, a multiple logistic regression with adjusted OR (AORs) with the corresponding of $95 \%$ confidence interval $(\mathrm{Cl})$ was obtained from following the multiple logistic regression for behaviors cervical cancer screening in relation to specific independent variables of interest (knowledge, husband support, social support, both external and internal motivation, all domains of health belief model, as well as the intention to uptake screening) after the adjustment for potential confounding factors in the models (age, education, occupation, income and cancer family history). At a p-value of 0.05, statistical SPSS version. 25 IBM (Armonk, NY, USA) significance was established. OR and $95 \%$ confidence intervals were used to express the direction and intensity of the association.

\section{Results}

This study enrolled a total of 410 respondents from Kediri, East Java. Approximately half of the study's $250(61.0 \%)$ participants were in the age range of 35 50 years. The majority of respondents $246(60.0 \%)$ were ISCED $\square 3$, and more than half $289(70.5 \%)$ were unemployed or housewife. The 251 (61.2 \%) and $395(96.3 \%)$, respectively, had monthly income of $\geq 1.47$ million. Our respondents also showed that mean (SD) was 4.89 (1.59) of knowledge, 15.62 (1.98) husband support, 4.77 (1.10) social support, external motivation 19.86 (3.33), and internal motivation 22.16 (2.61). Moreover, the mean (SD) value of them of perceived susceptibility, barrier, benefit, severity, self-efficacy, threat, and intention to screening were 16.32 (3.54), 23.04 (4.78), 23.13 
Winarti, E., et al. (2021)

(3.21), 20.65 (3.13), 27.06 (4.88), 25.73 (3.73), respectively (Table 1$)$.

The overall characteristics of the respondents are summarized in Table 2. No significant differences were noted in education, and income between groups outcome. However, significant difference in age, occupation, and cancer history was revealed between groups. Notably, the finding revealed that there were significantly different $(p<0.001)$ score in knowledge, support system, motivation, health belief models construct between group of behavior to uptake in screening variables (Table 2 ).

The univariate analysis revealed that knowledge, husband support, social support, both external and internal motivation, perceived susceptibility, barriers, benefits, severity, self-efficacy, and threat as well as the intention to uptake, had significant effects on behaviors to uptake in screening. Multiple logistic regression also shown knowledge, both external and internal motivation, perceived susceptibility, barriers, benefits, severity, self-efficacy, threat and intention. As shown in the adjusted OR for comparing the effects of variables on performance, the greatest impact belonged to social support. Also, internal motivation variable had a greater effect on behaviors than external motivation; and the individual's susceptibility had a greater effect on the behaviors than the perceived benefit after adjusted with covariate (Table 3 ).

\section{Discussion}

To the best of our knowledge, this case-control with multistage survey seems to be the first study engaging a validated questionnaire to investigate the health belief of screening cervical cancer as well as the factors affecting behavior toward screening for Indonesian women in Kediri, Indonesia. Furthermore, the highlight findings suggested that women's social support and intention was persistently related with behavioral to uptake the cervical cancer screening.

Prior study revealed that knowledge was significantly correlated with behaviors uptake cervical cancer screening, also indicated that the evaluating women's knowledge of cervical cancer implies putting the current aspect into consideration and suggest strategies for improved an understanding, attitudes, and demand for cervical cancer screening services (Weng, Jiang, Haji, Nondo, \& Zhou, 2020). Our study was also in line with previous studies among Ghanaian women which revealed that a large proportion $(93.6 \%$ and $97.7 \%$ ) of women in Ghana's central area lacking of knowledge of cervical cancer and screening, (Ebu et al., 2015). The pooled odds of knowledge score were 1.61 times greater for women who screened of cervical cancer than for those who do not conduct screening test. Similarly, with systematic review and meta-analysis among Ethiopian women with a favorable knowledge toward cervical cancer screening were 3.2 times more likely to have a test than those with a poor knowledge (Kassie et al., 2020). However, several studies conducted in various parts of Indonesia have revealed that the majority of women do not only have poor knowledge about cervical cancer screening tests, but also have lack of awareness about the illness itself (Endarti et al., 2018; Jaspers et al., 2011). Lack of knowledge and awareness is caused by the possibility that Indonesian women are lack of informing community education, low income status, and living in rural area (Spagnoletti, Bennett, Wahdi, Wilopo, \& Keenan, 2019). This implies that encouraging knowledge should be strategically undertaken.

Our findings regarding the relationship between support systems, including husbands and social support (family and friends), and screening uptake, highlight the importance of prevention strategies that include structured behavior change communication strategies that are sensitive to sociocultural beliefs, particularly patriarchal culture (Afsah, Astuti, Azizah, \& Muflihin, 2019), and aim to alleviate common misconceptions about the screening test, as well as health providers changing their husband and society. It is considered that the supposed receipt of social support encourages women to undertake routine cancer screenings, including the context of this area about belief and social norm. African American and other studies have discovered a positive correlation between subjective views of support for breast and cervical cancer screening (e.g., having supportive friends or family, including husband) and actual cancer screening behavior. On the other hand, persons who get social support may not regard it as beneficial, which may result in negative health implications such as psychological stress (Heaney \& Israel, 2008; Mouttapa et al., 2016). Another factor that discouraged women from screening was a lack of husband support (Ampofo, Adumatta, Owusu, \& Awuviry-Newton, 2020). A comprehensive review presented that the living experiences of family caregiver of women with gynecological cancer indicated that caregivers endure disturbance of daily routines, lifestyle, roles, physical closeness, and plans. Male partners' experiences caring for their wives/partners with breast and gynecological cancer represented that men prefer to minimize disturbances, focus on duties, and keep tension to themselves, which is viewed as being in line with masculinity, i.e. being the stronger person (Teskereci \& Kulakaç, 2018). Men claimed that going through the cervical cancer journey with their partner is lifealtering. Reorientation, change of life plans, intense care and support of partners, and increased practical obligations in their connections with women, the men mention a sense of interdependence and how the relationships have changed, notably in sexual terms. These findings ring true for hegemonic and compassionate masculinities alike (Oldertrøen Solli, de Boer, Nyheim Solbrække, \& Thoresen, 2019). Possible explanations for these findings include the fact that most women believe they do not exhibit disease-related signs and symptoms and hence 
Determining Behavior to Uptake and Its Predictors

do not view screening as critical. As a result, there may be a shortage of time to attend or even seek out facilities for screening (Ampofo et al., 2020). Consequently, promoting the social support and husband support are potentially effective strategies for improving screening test as well as mortality in the future and needed.

The outcomes of a logistic regression analysis strongly identified women's motivation to affect a cervical cancer screening. In line with study in China, it is shown that motivating also strongly related with cervical cancer screening and suggested that motivation can be utilized to policy standpoint into cervical cancer screening behaviors among Chinese women, with an emphasis on disease knowledge, certain demographic variables with screening test. These findings, also confirmed with that, can be used to build future intervention programs (Bai et al., 2018). Moreover, our research is consistent with the Fogg Conduct Model (FBM), which asserts that human behavior is motivated. Additionally, FBM states that a person will engage in the target behavior if he or she has adequate desire, the ability to engage in the action, and an effective trigger to engage in the action (Beilock, Feltz, \& Pivarnik, 2001). Currently, the motivation can improve the behaviors to positive cervical cancer screening.

In general, our findings indicated that the HBM constructs is a viable approach for investigating cervical cancer screening among Indonesian women. Additionally, our findings highlighted the critical nature of healthcare systems and practices that engagement perceived susceptibility, barriers, benefits, severity, self-efficacy, and threat to cervical screening for Indonesian women. Remarkably, it is vital to understand HBM constructs about cervical cancer and screening in order to develop and implement culturally appropriate screening programs (Lee, Roh, Jun, Goins, \& McKinley, 2020). The similar study shown a statistically significant favorable effect of perceived susceptibility on screening utilization. Women's low levels of perceived susceptibility contributed to their negative attitudes with low levels of cervical cancer screening test, which indicated that women who had low perceived susceptibility didn't really believe they were at risk of cervical cancer and also did not need the screening test (Sunarta, Sulaeman, \& Budihastuti, 2019).

The findings confirmed those of a prior study, which indicated a positive correlation between perceived severity and screening use. Additionally, previous study demonstrated that for women with a high perceived severity, it would result in a 0.11 times prevent in screening test compared to women with a low perceived severity (Sunarta et al., 2019). If someone perceives the severity of an illness, they will seek treatment and prevention. Women's perceptions of the severity of cervical cancer were formed by their experiences with the pain symptoms. In line with our study, the perceived benefits were a predictor of cervical cancer screening behavior in both univariate and multivariate models. In the final model, which produced more accurate results, perceived benefits were the best predictor of women receiving a screening test (Babazadeh et al., 2019). Perceived barriers and perceived severity were found to be predictive of cervical cancer screening successful test in Hope et al study (Hope, Moss, Redman, \& Sherman, 2017). Interestingly, both perceived threats, and perceived self-efficacy was the greatest factor of participants' screening cervical cancer test adherence. A previous study also established correlations between the HBM's theoretical constructs and self-efficacy. The results of Generalized Linear Modelling confirmed the theoretical associations between self-efficacy perceived threats with cervical cancer screening behavior. Women with a stronger sense of selfefficacy and low level of perceived threats were more likely to have had a screening test than those with a lower sense of self-efficacy and high perceived treat (De Peralta, Holaday, \& McDonell, 2015). This implies that encouraging HBM construct should be explored in strategical investigation.

Interestingly, our findings shown that intention associated with cervical cancer screening both multivariate and bivariate analysis, which indicated strong predictor to determine behavioral cervical cancer screening test in our population. This finding is congruent with a study conducted among Latinos. Perceived behavioral control was the largest predictor of intentions to get screened for cervical cancer, followed by subjective norms to be screened (Roncancio et al., 2015). According to a prior study, women's intention to utilize cervical cancer screening is primarily influenced by perceived behavioral control, followed by subjective norms on cervical cancer screening (Abamecha, Tena, \& Kiros, 2019). This assesses an intervention using the paradigm of implementation intentions shown that women recruited at England medical practice completed assessments of the theory of planned behavior variables before being induced to establish the implementation intentions identifying when, where, and how they would schedule the appointment. The results indicate that the theory of planned behavior factors and prior delayed behavior accurately predicted attendance. Despite similar motivation to attend, those who developed implementation intentions were much more likely to attend screening than controls. Additionally, evidence indicates that implementation objectives undermined the connection between antecedent delay and subsequent participation (Sheeran \& Orbell, 2000).

\section{Limitations}

As a limitation, the study could not consider other variables like birth control pills consumption, and parity frequency as predictors of the behavioral intention. The study was performed no attempt to establish causal relationships between these psychographic factors through an experimental 
approach. Additionally, the social desirability bias may impair the data's accuracy by influencing individuals' attitudes and intentions.

\section{Conclusion}

The knowledge, husband support, social support, both external and internal motivation, all domains of health belief model, as well as the intention to uptake screening were found strongly associated with behavioural to uptake cervical cancer screening. Our findings approaches may contribute in the earlier detection of cervical cancer and declining of cervical cancer-related mortality rates.

\section{Acknowledgment}

We would like to express our gratitude to all of the participants and Universitas Airlangga Ethical Committee for suggestion and approve ethical clearances our study, and to those who assisted us with data collection.

\section{Conflict of interest}

The author(s) declared no potential conflicts of interest with respect to the research, authorship, and/or publication of this article.

\section{Funding}

The author(s) received no financial support for the research, authorship, and/or publication of this article

\section{References}

Abamecha, F., Tena, A., \& Kiros, G. (2019). Psychographic predictors of intention to use cervical cancer screening services among women attending maternal and child health services in Southern Ethiopia: The theory of planned behavior (TPB) perspective. BMC Public Health, 19(1), 1-9. https://doi. org/10.1186/s12889-019-6745-X

Afsah, Y., Astuti, Y., Azizah, S., \& Muflihin, B. (2019). Javanese women's perception of husband's support in women reproductive health. Advances in in Health and Sciences Research, 15, 192-196. https://doi.org/10.2991/ icosihsn-19.2019.42

Aguinis, H., \& Harden, E. E. (2010). Sample size rules of thumb: Evaluating three common practices. In C. E. Lance \& R. J. Vandenberg (Eds.), Statistical and methodological myths and urban legends: Doctrine, verity and fable in the organizational and social sciences (pp. 267-360). Routledge/Taylor \& Francis Group

Ajzen, I. (1991). The theory of planned behavior. Organizational Behavior and Human Decision Processes, 50(2), 179-211. https://doi. org/10.1016/0749-5978(91)90020-T

Ampofo, A. G., Adumatta, A. D., Owusu, E., \& Awuviry-Newton, K. (2020). A crosssectional study of barriers to cervical cancer screening uptake in Ghana: An application of the health belief model. PloS One, 15(4), e0231459-e0231475. https://doi.org/10.1371/ journal.pone.0231459

Arbyn, M., Weiderpass, E., Bruni, L., de Sanjosé, S., Saraiya, M., Ferlay, J., \& Bray, F. (2020). Estimates of incidence and mortality of cervical cancer in 2018: A worldwide analysis. The Lancet Global Health, 8(2), e191-e203. https:// doi.org/10.1016/S2214-109X(19)30482-6

Babazadeh, T., Ghaffari-Fam, S., Oliaei, S., Sarbazi, E., Shirdel, A., Mostafa-Gharabaghi, P., \& Azizi, H. (2019). Predictors of Pap smear screening behavior among rural women in Tabriz, Iran: An application of health belief model. International Journal of Cancer Management, 12(5). e87246-e87254. https:// doi.org/10.5812/ijcm.87246

Bai, Y., Liu, Q., Chen, X., Gao, Y., Gong, H., Tan, X., ... Xiang, Q. (2018). Protection motivation theory in predicting intention to receive cervical cancer screening in rural Chinese women. Psycho-oncology, 27(2), 442-449. https://doi. org/10.1002/pon.4510

Bayu, H., Berhe, Y., Mulat, A., \& Alemu, A. (2016). Cervical cancer screening service uptake and associated factors among age eligible women in Mekelle Zone, Northern Ethiopia, 2015: a community based study using health belief model. PloS One, 11(3), e0149908-e0149921. https://doi.org/10.1371/journal.pone.0149908

Beilock, S. L., Feltz, D. L., \& Pivarnik, J. M. (2001). Training patterns of athletes during pregnancy and postpartum. Research Quarterly for Exercise and Sport, 72(1), 39-46. https://doi.or $\mathrm{g} / 10.1080 / 02701367.2001 .10608930$

Champion, V. L., \& Skinner, C. S. (2008). The health belief model. In K. Glanz, B. K. Rimer, \& K. Viswanath (Eds.), Health behavior and health education: Theory, research, and practice (pp. 45-65). Jossey-Bass.

Cohen, S., \& Lichtenstein, E. (1990). Partner behaviors that support quitting smoking. Journal of Consulting and Clinical Psychology, 58(3), 304-309. https://doi.org/10.1037/0022006X.58.3.304

Daryani, S., Shojaeezadeh, D., Batebi, A., Charati, J. Y., \& Naghibi, A. (2016). The effect of education based on a health belief model in women's practice with regard to the Pap smear test. Journal of Cancer Policy, 8, 51-56. https:// doi.org/10.1016/j.jcpo.2015.11.001

De Peralta, A. M., Holaday, B., \& McDonell, J. R. (2015). Factors affecting Hispanic women's participation in screening for cervical cancer. Journal of Immigrant and Minority Health, 17(3), 684-695. https://doi.org/10.1007/ s10903-014-9997-7

DeSantis, C. E., Bray, F., Ferlay, J., LortetTieulent, J., Anderson, B. O., \& Jemal, A. (2015). International variation in female breast cancer incidence and mortality 
Determining Behavior to Uptake and Its Predictors

rates. Cancer Epidemiology and Prevention Biomarkers, 24(10), 1495-1506. https://doi. org/10.1158/1055-9965.EPI-15-0535

Ebu, N. I., Mupepi, S. C., Siakwa, M. P., \& Sampselle, C. M. (2015). Knowledge, practice, and barriers toward cervical cancer screening in Elmina, Southern Ghana. International Journal of Women's Health, 7(1), 31-39. https://doi. org/10.2147/IJWH.S71797

Endarti, D., Satibi, S. A. K., Farida, M. A., Rahmawanti, Y., \& Andriani, T. (2018). Knowledge, perception, and acceptance of HPV vaccination and screening for cervical cancer among women in Yogyakarta Province, Indonesia. Asian Pacific Journal of Cancer Prevention: APJCP, 19(4), 1105-1111. https:// doi.org/10.22034/APJCP.2018.19.4.1105

Greibe Andersen, J., Shrestha, A. D., Gyawali, B., Neupane, D., \& Kallestrup, P. (2020). Barriers and facilitators to cervical cancer screening uptake among women in Nepal-a qualitative study. Women \& Health, 60(9), 963-974. https://doi.org/10.1080/03630242.2020.17817 42

Gu, C., Chan, C. W., He, G.-P., Choi, K., \& Yang, S.-B. (2013). Chinese women's motivation to receive future screening: the role of socialdemographic factors, knowledge and risk perception of cervical cancer. European Journal of Oncology Nursing, 17(2), 154-161. https://doi.org/10.1016/j.ejon.2012.04.005

Heaney, C. A., \& Israel, B. A. (2008). Social networks and social support. In K. Glanz, B. K. Rimer, \& K. Viswanath (Eds.), Health behavior and health education: Theory, research, and practice (pp. 189-210). Jossey-Bass.

Hope, K. A., Moss, E., Redman, C. W., \& Sherman, S. M. (2017). Psycho-social influences upon older women's decision to attend cervical screening: A review of current evidence. Preventive Medicine, 101, 60-66. https://doi. org/10.1016/j.ypmed.2017.05.002

Jaspers, L., Budiningsih, S., Wolterbeek, R., Henderson, F., \& Peters, A. (2011). Parental acceptance of human papillomavirus (HPV) vaccination in Indonesia: A cross-sectional study. Vaccine, 29(44), 7785-7793. https://doi. org/10.1016/j.vaccine.2011.07.107

Kassie, A. M., Abate, B. B., Kassaw, M. W., Aragie, T. G., Geleta, B. A., \& Shiferaw, W. S. (2020). Impact of knowledge and attitude on the utilization rate of cervical cancer screening tests among Ethiopian women: A systematic review and meta-analysis. PloS One, 15(12), e0239927-e0239949. https://doi.org/10.1371/ journal.pone. 0239927

Kementerian Kesehatan. (2017). Data dan Informasi Profil Kesehatan Indonesia 2016. Kementerian Kesehatan Republik Indonesia.

Lee, Y.-S., Roh, S., Jun, J. S., Goins, R. T., \& McKinley, C. E. (2020). Cervical cancer screening behaviors among American Indian women: Cervical cancer literacy and health belief model. Journal of Ethnic \& Cultural Diversity in Social Work, 30(5), 413-429. https://doi.org/10.1080/15313204.2020.17302 85

Mouttapa, M., Park Tanjasiri, S., Wu Weiss, J., Sablan-Santos, L., DeGuzman Lacsamana, J., Quitugua, L., . . . Tui'one May, V. (2016). Associations between women's perception of their husbands'/partners' social support and pap screening in Pacific Islander communities. Asia Pacific Journal of Public Health, 28(1), 61-71. https://doi.org/10.1177/1010539515613412

Muhith, A., Winarti, E., Perdana, S., Haryuni, S., Rahayu, K., \& Mallongi, A. (2020). Internal locus of control as a driving factor of early detaction behavior of servical cancer by inspection visual of acetic acid method. Open Access Maced J Med Sci. 8(E): 113-116. https://doi.org/10.3889/oamjms.2020.4341

Ogilvie, G. S., Smith, L. W., van Niekerk, D., Khurshed, F., Pedersen, H. N., Taylor, D., . . Franco, E. L. (2016). Correlates of women's intentions to be screened for human papillomavirus for cervical cancer screening with an extended interval. BMC Public Health, 16(1), 1-8. https://doi.org/10.1186/s12889016-2865-8

Oldertrøen Solli, K., de Boer, M., Nyheim Solbrække, K., \& Thoresen, L. (2019). Male partners experiences of caregiving for women with cervical cancer-a qualitative study. Journal of Clinical Nursing, 28(5-6), 987-996. https://doi. org/10.1111/jocn.14688

Rahayu, D. S., \& Ochoa, M. (2015). Cervical cancer awareness: an information dissemination campaign in indonesia. Jurnal Keperawatan Padjadjaran, 3(1). https://doi.org/10.24198/ jkp.v3i1.97

Reiss, S. (2012). Intrinsic and extrinsic motivation. Teaching of Psychology, 39(2), 152-156. https://doi.org/10.1111/1467-937X.00253

Rias, Y. A., Gordon, C. J., Niu, S. F., Wiratama, B. S., Chang, C. W., \& Tsai, H. T. (2020). Secondhand smoke correlates with elevated neutrophil-lymphocyte ratio and has a synergistic effect with physical inactivity on increasing susceptibility to type 2 diabetes mellitus: A community-based case control study. International Journal of Environmental Research and Public Health, 17(16), 56965617. https://doi.org/10.3390/ijerph17165696

Rias, Y. A., Kurniasari, M. D., Traynor, V., Niu, S. F., Wiratama, B. S., Chang, C. W., \& Tsai, H. T. (2020). Synergistic effect of low neutrophillymphocyte ratio with physical activity on quality of life in type 2 diabetes mellitus: A community-based study. Biological Research for Nursing, 22(3), 378-387. https://doi. org/10.1177/1099800420924126

Roncancio, A. M., Ward, K. K., Sanchez, I. A., Cano, M. A., Byrd, T. L., Vernon, S. W., . . . 
Winarti, E., et al. (2021)

Fernandez, M. E. (2015). Using the theory of planned behavior to understand cervical cancer screening among Latinas. Health Education \& Behavior, 42(5), 621-626. https:// doi.org/10.1177/1090198115571364

Rosenstock, I. M., Strecher, V. J., \& Becker, M. H. (1988). Social learning theory and the health belief model. Health Education Quarterly, 15(2), 175-183. https://doi. org/10.1177/109019818801500203

Sheeran, P., \& Orbell, S. (2000). Using implementation intentions to increase attendance for cervical cancer screening. Health Psychology, 19(3), 283-289. https://psycnet.apa.org/buy/200003769-009

Spagnoletti, B. R. M., Bennett, L. R., Wahdi, A. E., Wilopo, S. A., \& Keenan, C. A. (2019). A qualitative study of parental knowledge and perceptions of human papillomavirus and cervical cancer prevention in rural central Java, Indonesia: Understanding community readiness for prevention interventions. Asian Pacific Journal of Cancer Prevention: APJCP, 20(8), 2429-2434. https://doi.org/10.31557/ APJCP.2019.20.8.2429

Sunarta, E. A., Sulaeman, E. S., \& Budihastuti, U. R. (2019). Path analysis on the determinants of visual inspection acetic acid utilization on early detection of cervical cancer: application of health belief model theory. Journal of Health
Promotion and Behavior, 4(1), 32-42. https:// doi.org/10.26911/thejhpb.2019.04.01.04

Teskereci, G., \& Kulakaç, O. (2018). Life experiences of caregivers of women with gynaecological cancer: A mixed-methods systematic review. European Journal of Cancer Care, 27(1), e12456-e12473. https://doi.org/10.1111/ ecc. 12456

Waller, J., Ostini, R., Marlow, L. A., McCaffery, K., \& Zimet, G. (2013). Validation of a measure of knowledge about human papillomavirus (HPV) using item response theory and classical test theory. Preventive Medicine, 56(1), 35-40. https://doi.org/10.1016/j.ypmed.2012.10.028

Weng, Q., Jiang, J., Haji, F. M., Nondo, L. H., \& Zhou, H. (2020). Women's knowledge of and attitudes toward cervical cancer and cervical cancer screening in Zanzibar, Tanzania: a cross-sectional study. BMC Cancer, 20(1), 6375. https://doi.org/10.1186/s12885-020-6528-x Zare, M., Ghodsbin, F., Jahanbin, I., Ariafar, A., Keshavarzi, S., \& Izadi, T. (2016). The effect of health belief model-based education on knowledge and prostate cancer screening behaviors: a randomized controlled trial. International Journal of Community Based Nursing and Midwifery, 4(1), 57-68. https:// www.ncbi.nlm.nih.gov/pmc/articles/ PMC4709816/ 